\title{
A CRITICAL ANALYSIS
}

\author{
Joanna Cullinane \\ Centre for Labour and Trade Union Studies \\ University of Waikato
}

\begin{abstract}
Since the 1970-80s, employment relationships in the western world have been influenced by the emergence of human resource management (HRM) which has, to some degree, challenged the existing order-industrial relations (IR). The debate resulting from the emergence of HRM has kept the academic presses churning. At one level, there is a 'co-existence' debate which explores the likelihood that HRM will supplant IR. At another level, debate focuses on the 'distinctiveness' of HRM from IR and/or personnel management theory. However, the debates between the HRM and IR fields have only been intra-discourse; HRM literature has been almost silent on the subject of IR, while IR has had little to say about HRM. This, despite the fact that it could be argued that IR and HRM are simply different views of the same set of phenomena. Neither the HRM or IR fields seem able to incorporate the strengths of the other. By mapping the underlying paradigms of these two fields, this paper explores the question: 'What makes the fields of HRM and IR unable to articulate?'
\end{abstract}

Since the 1980s, Human Resource Management (HRM) has been adopted in organisations of the western capitalist world. It has challenged the existing order of management - personnel management as the preferred employment management technique of organisations, and has arguably reached hegemonic ${ }^{1}$ proportions. Questions of how and why HRM has become hegemonic have never been sufficiently explained in academic literature to date (Ezzamel, Lilley, Wilkinson, Willmott, 1996). Relatedly, efforts at defining HRM have also been largely unsuccessful and have resulted in some speculation that there is nothing new created as a result of HRM to define.

For some, HRM is simply a relabelling of personnel management (Guest, 1989) an attempt to repackage the discipline into a form that distances the adversarial relations of the past. This non-adversarial repackaging goes some way towards explaining the rejection of industrial relations as a complementary discipline. Another view is that $\mathrm{HRM}$ is an approach to employment governance ${ }^{2}$ based on tenets ${ }^{3}$ quite different from those of personnel management (Boxall, 1996). For this second group, HRM is not a fad or 'old wine in new bottles' but represents a significant and different way of managing workers.

Which of these two views is accurate? On one hand, there is a huge degree of overlap between the functions, theories and models which form the disciplines ${ }^{4}$ of HRM and personnel management. The overlap supports the repackaging argument on the assertion that the content of the field has not changed. On the other hand, there are outcomes associated with HRM that have not necessarily accompanied personnel management traditionally, for example, strategic orientations, normative concepts, cultural control etc. So there is merit on both sides of the issue.

This paper is posited on an assumption that both views are correct but at different levels. The argument that HRM is personnel management functions relabelled is perhaps an appropriate description at the level of a discipline. As often noted in critical comment on HRM, the text books that detail the functions, theories and models of the HRM discipline are so similar to those of personnel management that there is some suspicion that only the covers of these new books have been changed. But at a level wider than the functions of the discipline, HRM has a discourse ${ }^{5}$ which is different from the discourse of personnel management. The distinctiveness of HRM arises not out of difference with personnel's basic models and theories, but in the way in which those models and theories are deployed (Townley, 1993).

A clear example of this distinction between the discipline and discourse of HRM is the treatment of unions. The internal theories of bargaining, union involvement etc within both the personnel and HRM disciplines are very similar, but the treatment of unions within the era of personnel management was much different than is currently the norm under HRM. If the foundation theories of the disciplines are the same, why then is the treatment of unions so different? The answer lies in the difference between personnel and HRM discourses. The personnel discourse has tenets which are predominantly pluralist, collective and corporatist, while the HRM discourse has tenets that are unitarist, utilitarian and anti-collective (Guest, 1989, Storey, 1996). These 
tenets combine into styles of employment governance in which parts of the disciplines are selectively applied according to how well they support the overall philosophy of the discourse.

The separation of HRM discipline and discourse provides a starting point for defining HRM (see figure one). The discipline part of HRM can be found in the multitude of personnel-HRM text books that abound in the academy. But the discourse of HRM is a different matter. This area offers huge potential for insights into HRM, but there has been only limited work done on mapping the styles of the HRM discourse. ${ }^{6}$

The two most well known styles of HRM discourse widely discussed to date are the Harvard School developed first by Beer and colleagues in 1984 and the Michigan School developed by Fombrun et al. also in 1984. If we map the basic tenets of these two styles of HRM discourse, we can start to block-in the conceptual space they occupy within the HRM discourse. This will eventually allow us to map the discourse and define HRM. For illustration: Harvard emphases 'soft' human aspects of employment governance, and Michigan emphasising 'hard' strategic aspects of employment governance.

The Harvard School draws its academic lineage from the human relations school, consequently emphasises communication, teamwork and the utilisation of individual talents (Blyton \& Turnball, 1992). It stresses the human potential and purposefully rejects 'instrumental values about people' (Beer, Spector, Lawrence, Mills \& Walton, 1984). The discipline of HRM under Harvard styles are organised towards 'developmental humanism' and the recognition of multiple stakeholders. Employment governance under this style of HRM discourse is organised with maximisation of commitment as a primary goal.

Comparatively, the Michigan School lays more emphasis on a style of employment governance that views workers as resources to be utilised by the organisation. It organises employment governance as a sub-function of strategic management ${ }^{7}$, leading to philosophies of HRM that are instrumental and utilitarian. In this model, workers are resources that must matched to the identified strategy of the organisation, and be controlled to ensure attainment of strategic goals (Boxall, 1996).

Beyond the Harvard and Michigan schools, there has been little work to categorise styles of HRM discourse according to a defining base of tenets. Yet for instance, in New Zealand alone, we have the Workplace Reform proponents who have a degree of commonalty in the employment governance they pursue. There are also multi-national organisations which pursue Japanese and American styles of HRM, and there are organisations in the reformed state sector which pursue their own brand of HRM. These are approaches to employment governance which are identifiable, discernible and unique styles of HRM discourse which could be used to define HRM as it exists, for example, in New Zealand.

\section{Figure 1. Representation of discipline vs discourse}

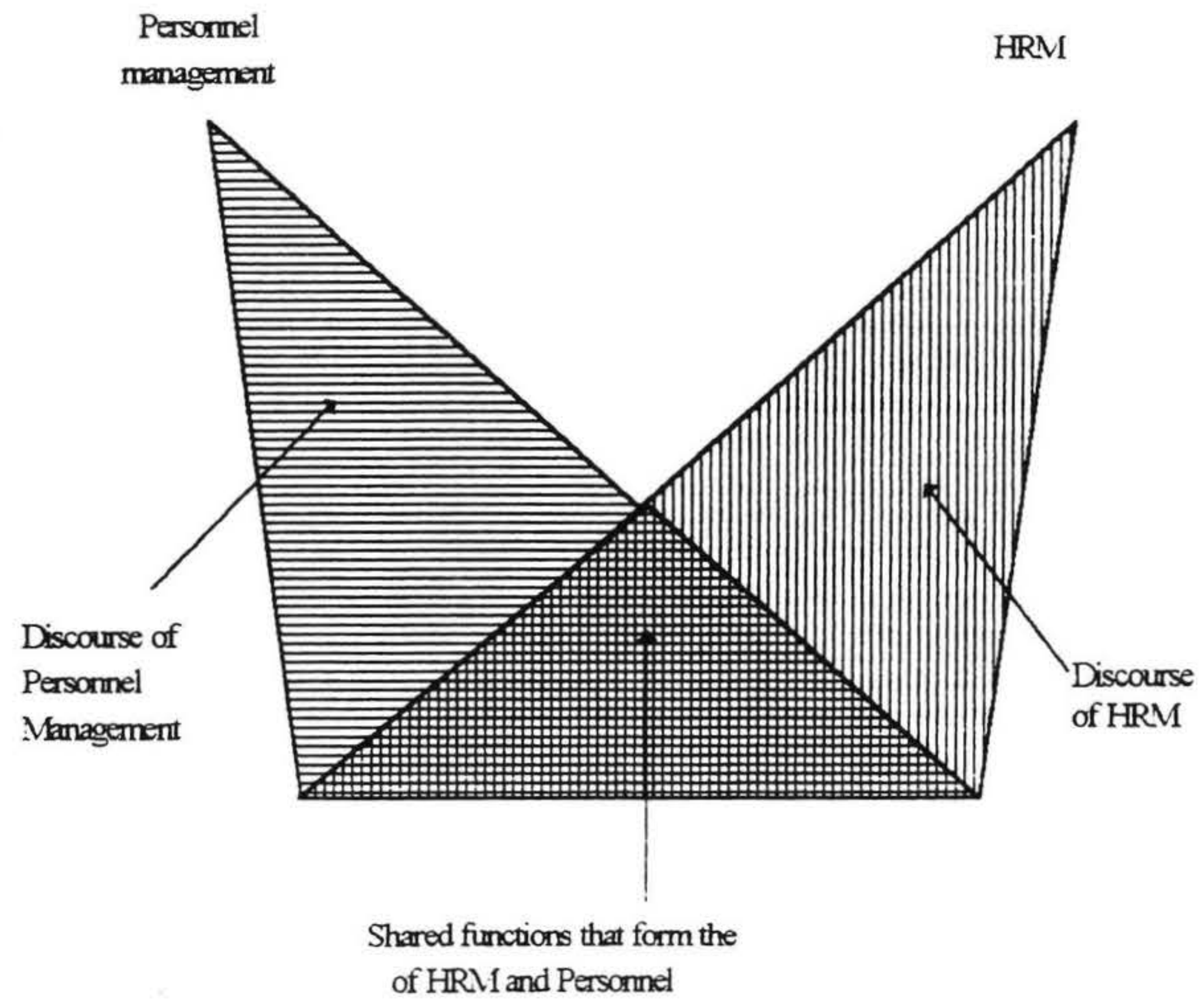


A pre requirement to defining HRM as a set of discourse styles is to delineate the parameters in which they operate. This will provide a framework of the operating environment of HRM. The framework utilised in this paper combines Regulation Analysis ${ }^{8}$ and labour process theory to contribute to a critical definition of HRM. ${ }^{9}$ This framework and the conclusions drawn from it are exploratory and should be viewed as starting points to further work in defining HRM.

\section{Regulation Analysis}

Given that HRM is a tool of management in capitalist society, the place to start in pursuing a critical definition of HRM is at the level of political economy. In this instance, utilising a Regulation Analysis, we can gain some insights into the macro parameters in which HRM operates.

The starting point of Regulation Analysis is a Marxist tenet that capitalism is inherently unstable and prone to collapse if unregulated (Boyer, 1990). This being the case, the Regulationists pose the question; how does capitalism survive? The answer they offer is that capitalist political economies are sustained through structures of stability built on social and political mechanisms. The combination of social and political mechanisms which delay the crisis of a capitalist system also become the defining feature of that capitalist system. These mechanisms, called modes of regulation, support and define the capitalist superstructure which is called a regime of accumulation.

An accumulation regime is a particular combination of consumption and production which is relatively stable over time. It is the environment through which modes of regulation are created and sustained and through which the tendency towards crisis in capitalism is delayed. Modes of regulation operate at numerous levels; social, economic, political, technological, regional, etc, and are the result of compromise which institutionalises social contestation.

The best documented regime of accumulation is Fordism. This is a regime that was "dominant in North America and in much of northern Europe during the first thirty years of the post-war period' (Peck \& Miyamachi, 1994,p. 643). Fordism was an intensive regime of accumulation that combined Keynesian economic policy and Taylorist technological paradigms into a dynamic system of mass consumption and production lubricated by sustained increases in productivity and standards of living.

Fordist style macro systems of government included welfare systems ${ }^{10}$ and Keynesian economic stabilisation. Most national Fordisms in the Western capitalist world translating these into corporatist, (sometimes) tripartite, and frequently statist systems of social and industrial organisation. In terms of the ambit of this paper, these Fordist systems of organisation bred and supported theories of employment governance with philosophies of complementary natures. Hence humanist oriented personnel management and Donovan ${ }^{11}$ style industrial relations models.

The link between productivity and real improvement in standards of living - the Fordist class compromise - became a defining feature of the Fordist mode of regulation. When this compromise was destabilised (reaching of the upper limits of productivity growth), the structures of regulation weakened, and the Fordist regime of accumulation went into crisis. As a result, the systems of industrial relations and employment governance that formed part of the mode of regulation of Fordism started to lose their context of operation. It has been the process of forming a new regime of accumulation in western capitalism (after-Fordism) that has resulted in the development of alternative methods of employment governance and in particular HRM.

New regimes of accumulation demand new modes of regulation, causing new systems and structures of organising society at all levels. In New Zealand, Fordism was never a completely integrated regime. ${ }^{12}$ Because of this the crisis of the Fordism internationally system hit New Zealand with brutal force - we did not have the protective impetus of our own internal circle of production and consumption. Massive restructuring at all levels in New Zealand political economy has followed, and the still developing regime of accumulation in New Zealand is radically different from the previous colonial Fordism.

So, in terms of a Regulationist view, the style of discourse in HRM has wider implications for the regime of accumulation than in the employment governance of an enterprise alone. HRM contributes to determining the mode of regulation in capitalism and as such the style of discourses adopted affect the macro structure of capitalism.

\section{Labour Process Theory}

Part of the development of a new New Zealand regime of accumulation has been the reconstruction of national patterns of production and consumption. A key part of this new regime of accumulation has been the reform of labour processes. This is perhaps best typified by employer reactions following the introduction of the Employment Contracts Act (ECA) in New Zealand. We all know the effect ${ }^{13}$ of the ECA on trade unions and the labour market. Most of us are aware of the resulting effect on management styles.

The discipline of labour process analysis can assist us to order these impressions of how employment governance has changed. In the last decade, labour process theory has moved on from the foundations laid by Braverman in the deskilling thesis. It is now generally accepted within the labour process discipline that there is no universal approach to employment governance (Newton \& Findlay, 1996) and that management will use a variety of approaches to control the workplace. But the basic tenets of labour process theory remain relevant. First, capital must control the labour process in order to maximise the transformation of labour power into labour (see Braverman and Marx). Second, management is the means capital uses to control the labour process and maximise the transformation of labour power, and third, management divides work into component parts to assist control of the labour process (Thompson, 1983). 
The move away from Braverman's deskilling thesis reflects the dissolution of the Taylorist aspects of Fordism. With the crisis of Fordism, and the reformation of production processes, Taylorism has become just one of a number of possible techniques utilised by management. Modern labour process theory reflects this (Knights \& Willmott, 1990). It seems probable that there may never again be an integrating regime of accumulation that reaches hegemonic status. If this is the case, then there is never again likely to be one normative style of labour process or production organisation.

Employment governance is the 'sharp' end of the control of the labour process. So, HRM as a tool of management (within capitalism) is a means of controlling the labour process. The style of HRM discourse pursued dictates how management is controlling the labour process. This is best explained using the illustrations of the Harvard style of HRM. The Harvard style of HRM displays tendencies towards developmental humanism. This means that the Harvard style of labour process stresses cooperative and not overtly coercive employment governance. Employees are 'encouraged' to provide surplus value of their own free will ${ }^{14}$ through careful control of cultural levers within organisations (Blyton and Turnball, 1992). Management does not need stand over tactics to control the labour process because the style of employment governance ensures that workers themselves maximise the transformation of labour power.

Within an after-Fordist environment labour processes will reflect pragmatic and strategic responses to operating environments. The range of disciplines of HRM adopted reflects this fact. Taylorism may still be a contingent response to certain environments and in certain regions and industries, but it will probably not be the best response for all situations. In New Zealand, certain factors from our developing regime of accumulation will impact on the predominant labour process. One key factor that will affect the labour processes and style of employment governance adopted in New Zealand is the move to a reformed role for the state. With a comparatively large pool of unskilled and semi-skilled workers in New Zealand, state traditions of welfarism and paternalism have acted to mediate exploitation in the labour market and over-intensification of the labour process. These projections have been eroded under the developing regime of accumulation in New Zealand. The downstream effect of government reform is likely to be intensification of the labour process and a discourse of HRM that treats unskilled workers as exploitable resources.

The other side of that coin is that there is also a comparative shortage of skilled workers that is likely to be exacerbated within the environment of devolved industry training and qualification. This shortage will necessitate labour processes and HRM discourses that treat skilled workers as scarce resources, to be retained and nurtured at all costs. But there are implications beyond these; the adoption of a market driven after-Fordist regime of accumulation in New Zealand will affect the whole structure of society. For instance, adoption of HRM discourses that embrace individual em- ployment at the expense of collectivity will impact more widely than on unions and employment governance alone.

\section{Concluding comments}

HRM has become an umbrella term to describe a number of distinct approaches to employment governance. In order to define it, we must differentiate between HRM, the discipline, and HRM as a discourse. A necessary part of the definition process is mapping out the approaches of the various styles of HRM within the discourse. In New Zealand alone, there are a whole raft of styles of employment governance which fall under the banner of HRM, including workplace reform, Harvard, Michigan, Japanese and America approaches.

As a starting point, this paper has developed a partial framework for defining HRM within it's operating context. Using a Regulationist approach, we see that HRM is part of a mode of regulation that sustains and is sustained by a capitalist regime of accumulation. As such, HRM is at the same time one of the forces that shape the capitalist structure in a nation, a dependent upon that structure for an operating environment which ensures survival. Regulation analysis in part explains the rise of HRM - it has developed out of the Fordist crisis which has limited the operating context for both personnel management and Donovan style industrial relations. This means that what ever regime of accumulation replaces or has replaced Fordism is likely to incorporate HRM as a component of social regulation.

The Fordist crisis has caused, and was caused by, limitations in the Taylorist labour process. If the wide diversity of styles of HRM are any indication, there will be no single form of employment governance or labour process to replace Fordism. This means that in order to define HRM it will be necessary to map out basic tenets or philosophies of various approaches as opposed to looking for a single sentence definition.

\section{Future research}

Obviously, this paper is exploratory and abstract. Further work needs to be done on refining these central ideas. Empirical research may be relevant in mapping the tenets of the styles of HRM, particularly in New Zealand where the developing mode of accumulation is likely to be "cutting edge'.

For the author, this is an exploratory piece of work for a thesis. The next areas to be explored on similar themes to this paper are industrial relations, and the developing discipline of employment relations. I did originally see merit in including some method of deconstruction along Foucoultian lines as part of this paper - developing from the labour process section into a 'How do they do it?' area, this would still be relevant.

\section{Notes}

1. Def: Leading or ruling as supreme. In this sense I use 
hegemonic to denote a change from being one strategy or approach among many possible approaches to being an approach that sets a normative benchmark for others to follow.

2. Employment governance is the term used within this paper to denote the systems processes and relationships of managing workers.

3. Def: principles on which a belief or theory is based

4. Def: a particular area of study, instruction or learning with established theories, models and rules.

5. Def: concept which defines a field of knowledge as wider than the discipline's rules and theories, and incorporates the structures and principles through which the discipline is organised.

6. With the specific exception of Storey, 1992 who has contributed much with the Hard-Soft model.

7. Specifically the strategic management 'design school' which is posited on the matching of internal and external environments.

8. Also called French Regulation or Regulation School. See Boyer, 1990, Lipietz, 1992, Peck and Miyamachi, 1994.

9. The disciplines contributing to the framework will be defined later within text.

10. Of varying degrees.

11. See Guest, 1991 for explanation of Donovan style industrial relations.

12. Probably best described as quasi-Fordist because our national Fordism was reliant on the largesse of hegemonic Fordist nations like USA for the trickle down sustaining our production and consumption cycles.

13. Or more accurately the trends because of the opacity of statistical information in this area.

14. See Barker and Burawoy.

\section{References}

Beer, M., Spector, B., Lawrence, P., Mills, Q. \& Walton, R. 1984. Managing Human Assets. New York: Free Press.

Blyton, P. \& Turnbull, P. (eds) 1992. Reassessing human resource management. London: Sage.

Bonefeld, W. \& Holloway, J. (eds) 1991. Post-Fordism and social form. A Marxist debate of the postFordist state. London, Macmillan.
Boxall, P. 1996. The strategic HRM debate and the resource view of the firm. Human resource management journal, 6, 3, 59-75.

Boyer, R. 1990. The regulation school: a critical introduction. New York: Columbia University Press.

Braverman, H. 1974. Labour \& Monopoly Capital, Monthly Press Review, New York.

Ezzamel, M., Lilley, S., Wilkinson, A. \& Willmott, H. 1996. Practicalities in human resource management. Human Resource Management Journal, 6 , $1,63-80$.

Fomburn, C., Tichy, N. \& Devanna, M. 1984. Strategic human resource management. New York: John Wiley.

Guest, D. 1989. Personnel and HRM: can you tell the difference? Personnel Management, 21, 1, 4851.

Knights, D. \& Willmott, H. Eds. 1990. Labour process theory. London: MacMillian.

Lipietz, A. 1992. Towards a new economic order: postfordism, ecologyand democracy. Cambridge, Polity Press.

Peck, J. \& Miyamachi, Y. 1994. Regulating Japan? Regulation theory versus the Japanese experience. Environment and planning D: Society and Space, 12, 639-674.

Storey, J. 1996. From personnel management to HRM: The implications for teaching. Asia Pacific Journal of Human Resources, 33, 3, 4-14.

Thompson, P. 1983. The Nature of Work. London: MacMillian.

Townley, B. 1993. Foucault, power/knowledge, and its relevance for human resource management. Academy of Management Review, 18, 3, 518-545.

\section{Author}

Joanna Cullinane is a Lecturer at the Centre for Labour and Trade Union Studies, University of Waikato, Private Bag 3105, Hamilton.. 